\title{
Strategi Pengelolaan Perikanan Tuna Di Kabupaten Pulau Morotai (The strategy of tuna fisheries management in Regency of Morotai Island)
}

\author{
Titien Sofiati ${ }^{1}$, Djainudin Alwi ${ }^{2}$ \\ ${ }^{1}$ Program Studi THP, FPIK-UNIPAS Morotai, Morotai \\ ${ }^{2}$ Program Studi Ilmu Kelautan, FPIK-UNIPAS Morotai, Morotai \\ e-mail: titian_sofiati@yahoo.com
}

\begin{abstract}
ABSTRAK
Tujuan dari penelitian adalah merumuskan alternatis strategi prioritas pengelolaan perikanan tuna di Kab. Pulau Morotai. Adapun manfaat yang diperoleh antara lain sebagai rekomendasi bagi PEMDA Kabupaten Pulau Morotai melalui Dinas Kelautan dan Perikanan Pulau Morotai untuk pengembangan perikanan tuna. Penelitian dilakukan di Kabupaten Pulau Morotai selama tida bulan yaitu bulan Juni-Agustus 2018.Pengumpulan data dilapangan menggunakan metode survei.Dimana data yang diperoleh terdiri dari data primer dan data sekunder.Altaernatif strategi menggunakan analisis SWOT dengan terlebih dahulu mengidentifikasi faktor eksternal dan faktor internal usaha perikanan tuna di Kab. Pulau Morotai.

Hasil identifikasi dan pembobotan serta skoring faktor internal memberikan nilai sebesar 2,834, sedangkan hasil skoring faktor eksternal sebesar 3,327. Berdasarkan nilai tersebut dari keempat alternative strategi yaitu strategi SO, Strategi ST, strategi WO, dan strategi WT, diperoleh strategi prioritas untuk pengelolaan adalah strategi SO.Strategi prioritas pengelolaan perikanan tuna di Kab. Pulau Morotai terdiri dari: (1) Menerapan model pengelolaan perikanan tuna terpadu; (2) Membuka peluang pasar melalui penetapan alur bisnis perikanan tuna dengan investor dari luar Kabupaten Pulau Morotai (dalam maupun luar negeri); (3) Manajemen pengelolaan yang baik, melalui program Koperasi nelayan.
\end{abstract}

Kata Kunci: Strategi pengelolaan, perikanan tuna, Kab. Pulau Morotai.

\begin{abstract}
The purpose of this research is to formulate the alternative management priority strategy of tuna fisheries in Regencyn) of Morotai Island. The advantage that can get is none others as a recommendation to the government of the Regancy of Morotai Island through the Marine and Fisheries Service of Morotai Island for developing the fishing of tuna. This research takes the place in Regency of Morotai Island for three months, from June to August on 2018. The collecting data in field use the survey method. The collected data divided into primary data and secondary data. The alternative strategy used the SWOT analysis, firstly, to identify the external and internal factors of tuna fisheries business in Regency of Morotai Island.

The result of identification and weighting, also the scoring of internal factor gives the value 2,834 , whereas the scoring result of external factor is 3,327. According to the value of four alternative strategies, there are SO strategy, ST strategy, WO strategy, and WT strategy, which obtained to be the management of priority strategy that is the SO strategy. The priority strategy of tuna fisheries management in Regency of Morotai Island that consisted of: (1) Apply the integrate priority management of tuna fisheries; (2) Open the big opportunities through determination of business streams of tuna fisheries with the outside investors form Regency of Morotai Island ( in or outside country); (3) Good management from fishing cooperation program.
\end{abstract}

Keywords: Management strategy, tuna fisheries, The Regency of Morotai Island. 


\section{Pendahuluan}

Peraturan Pemerintah Republik Indonesia No 50 tahun 2014 tentang kawasan Ekonomi Khusus (KEK) dan Permen Perindustrian Republik Indonesia No 71/M-IND/PER/12/2013 Tentang pengembangan industri di Kabupaten Pulau Morotai, memberi kebebasan penuh bagi pemerintah daerah dalam mengembangkan potensi dari berbagai sektor. Pada sektor perikanan, pembangunan difokuskan pada pengembangan sumberdaya ikan Tuna yang potensinya melimpah di perairan Morotai. BPS Kab. Pulau Morotai (2015) menyebutkan bahwa total produksi tuna di perairan Morotai pada tahun 2014 sebesar 1219,3 ton. Tren produktivitas penangkapan yang menurun mengindikasikan bahwa pemanfaatan sumberdaya tuna masih belum optimal (Sofiati. 2016)

Tuna merupakan ikan ekonomis penting di Indonesia.Daerah yang menjadikan tuna sebagai fokus pengelolaan harus melakukan banyak persiapan.Pengelolaan tuna tidak dapat disamakan dengan pengelolaan sumberdaya ikan lainnya, hal ini dikarenakan tuna merupakan komoditi eksport yang membutuhkan penanganan ekstra.Penyediaan sarana dan prasaran yang memadai juga harus dipersiapkan oleh pemerintah daerah.Kerjasama antar daerah pengelola tuna juga harus dijalin, mengingat tuna adalah ikan yang daerah ruayanya sangat luas.Dibutuhkan suatu strategi pengelolaan terpadu untuk memanfaatkan sumberdaya ikan ini.

Tujuan dari penelitian adalah merumuskan alternatis strategi prioritas pengelolaan perikanan tuna di Kab. Pulau Morotai. Adapun manfaat yang diperoleh antara lain sebagai rekomendasi bagi PEMDA Kabupaten Pulau Morotai melalui Dinas Kelautan dan Perikanan Pulau Morotai untuk pengembangan perikanan tuna.

\section{Metode penelitian}

\subsection{Waktu dan tempat penelitian}

Penelitiandilakukan di Kabupaten Pulau Morotai. Studi pendahuluan dilakukan selama 1 bulan pada bulan Juni 2018. Pengumpulan data di lokasi penelitian dilakukan selama 2 bulan, yakni bulan Juli sampai Agustus 2018. Lokasi penelitian dapat dilihat pada Gambar 1.

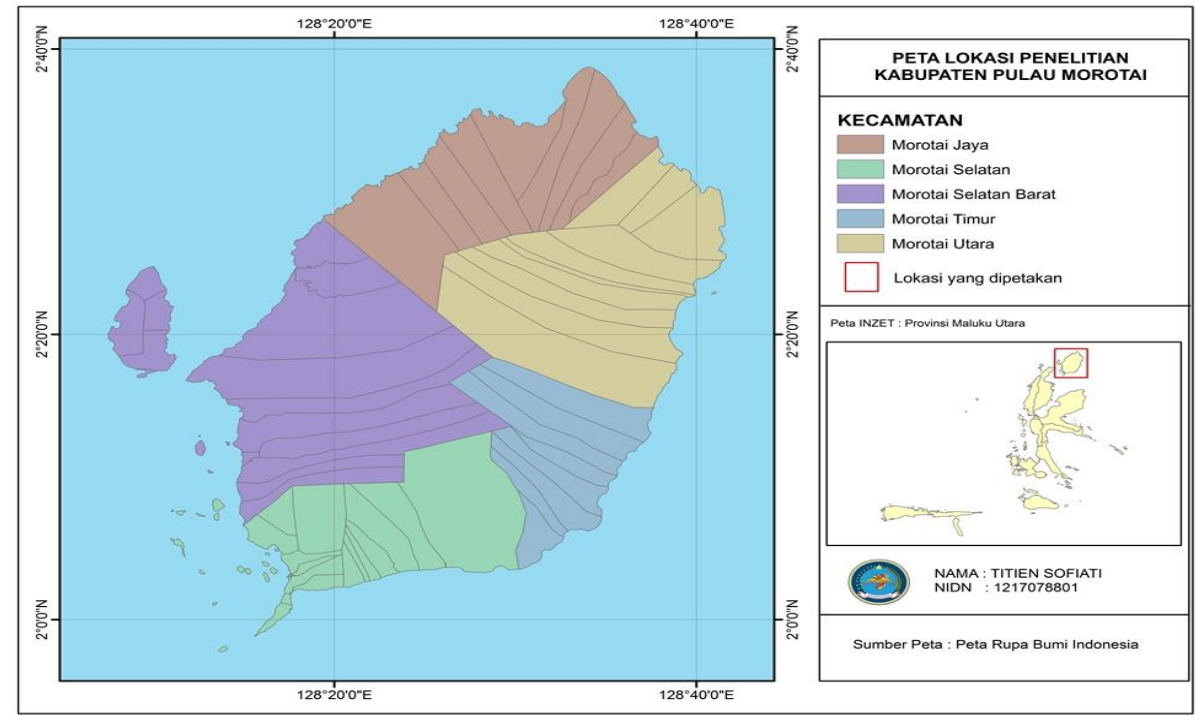

Gambar 1. Peta lokasi penelitian 
ISSN 2620-570X

JURNAL IlMU KelAUtAN KEPULAUAN, 1 (2) ;22-29, DeSEMBER 2018

\subsection{Prosedur Penelitian}

Strategi pengelolaan perikanan tuna dapat dilihat dengan melakukan analisis faktor internal dan faktor eksternal. Rumusan startegi pengelolaah diperoleh dengan analisis SWOT. Pengumpulan data dilapangan menggunakan metode survei.Dimana data yang diperoleh terdiri dari data primer dan data sekunder.Data primer merupakan data hasil wawancara semi terstruktur para pelaku usaha penangkapan tuna.Penentuan responden dilakukan secara sengaja (proposive sampling) yang mewakili stakeholder perikanan tuna, terdiri dari Kepala DKP Kab. Pulau Morotai, Kasubak Tangkap DKP Kab. Pulau Morotai, Kepala Koperasi Perikanan, pengempul, dan nelayan tuna.Wawancara semi terstruktur pada pelaku perikanan tuna bertujuan untuk memperoleh gambaran faktor-faktor yang mempengaruhi pengelolaan tuna baik internal maupun eksternal.Dari hasil petakan faktor internal dan eksternal kemudian dilanjutkan dengan analisis perumusan strategi menggunakan SWOT. Data sekunder merupakan data pendukung berupa data time series hasil tangkapan, RTP, Armada, dan data harga ikan. Data sekunder diperoleh dari DKP Kab.Pulau Morotai, Lock book Koperasi perikanan, dan data statistik yang di dapat secara daring.

\subsection{Analisis data}

Faktor internal (kekuatan dan kelemahan) dan faktor eksternal (peluang dan ancaman) perikanan tuna dimasukan dalam matrik Internal Factors Analysis Summary (IFAS) yang terdiri dari faktor kekuatan dan kelemahan dan matriks External Factors Analysis Summary (EFAS) yang terdiri dari faktor peluang dan ancaman (Tabel 1).

Tabel 1. Matriks IFAS/EFAS

\begin{tabular}{|l|l|l|l|}
\hline Faktor Internal & Bobot & Rating & Skor Pembobotan \\
\hline 1. Kekuatan & & & \\
\hline & & & \\
\hline 2. Kelemahan & & & \\
\hline & & & \\
\hline Total & 1.0 & & \\
\hline
\end{tabular}

Penyusunan matriks IFAS dan EFAS (Nurani. 2010):

1. Melakukan identifikasi faktor-faktor internal dan eksternal

2. Pembobotan terhadap masing-masing faktor dimulai dari 1,00 (sangat penting) sampai dengan 0,00 (tidak penting). Total bobot keseluruhan faktor adalah 1,00.

3. Pemberian rating untuk masing-masing faktor tergantung pada pengaruh faktor terhapap permasalahan. Nilai rating mulai dari 4 (outstanding) samai 1 (poor).

a. Faktor internal: Pemberian rating faktor kekuatan bersifat positif, semakin besar kekuatan semakin besar rating diberikan. Faktor kelemahan bersifat negative, semakin besar kelemahan makan semakin kecil rating yang diberikan. 
b. Faktor eksternal: Pemberian rating faktor peluang bersifat positif, semakin besar peluang semakin besar rating diberikan. Faktor ancaman bersifat negative, semakin besar kelemahan semakin kecil rating diberikan.

4. Dilakukan perkalian bobot skor dan rating.

5. Jumlah dari skor terbobot menentukan kondisi internal sistem

a. Faktor internal: jika total skor $\geq 2,5$ artinya kondisi internal sistem memiliki kekuatan untuk mengatasi situasi.

b. Faktor eksternal: jika total skor $\geq 2,5$ berati kondisi sistem mampu merespon kondisi eksternal yang ada.

Alternatif strategi pengelolaan dapat dirumuskan dengan menyusun matriks SWOT. Matriks SWOT dapat dilihat pada Tabel 2.

Tabel 2. Matriks SWOT

\begin{tabular}{|l|l|l|}
\hline OFAS & Strength (S) & Weakness (W) \\
\hline Opportunities (O) & Strategi SO & Strategi WO \\
\hline Threats (T) & Strategi ST & Strategi WT \\
& & \\
\hline
\end{tabular}

\section{III.Hasil dan pembahasan}

\subsection{Analisis Faktor Internal dan Eksternal Perikanan Tuna di Kabupaten Pulau Morotai}

Analisis faktor internal dan eksternal bertujuan untuk mengidentifikasi faktor-faktor yang berpengaruh pada pengelolaan perikanan tuna.Faktor internal terdiri dari kekuatan (strength) dan kelemahan (weaknesses), sedangkan faktor eksternal terdiri dari peluang (opportunities) dan ancaman (threats).Hasil identifikasi dan pembobotan serta skoring dari faktor internal dan eksternal pada perikanan tuna di Kabupaten Pulau Morotai dapat dilihat paga Tabel 3.dan Tabel 4.

Table 3. Matriks faktor internal (IFAS) perikanan tuna di Kabupaten Pulau Morotai

\begin{tabular}{|c|c|c|c|c|}
\hline \multicolumn{5}{|c|}{ FAKTOR STRATEGI INTERNAL } \\
\hline & (Kekuatan) & Bobot & Peringkat & Skor \\
\hline S1 & Potensi Sumberdaya Ikan Besar & 0.11 & 3.70 & 0.397 \\
\hline S2 & Nilai Jual Tinggi & 0.10 & 3.60 & 0.376 \\
\hline
\end{tabular}


ISSN 2620-570X

JURNAL IlMU KelAUtAN KEPULAUAN, 1 (2) ;22-29, DeSEMBER 2018

\begin{tabular}{llccc} 
S3 & Potensi SDM Memadai & 0.10 & 3.30 & 0.316 \\
S4 & Jumlah nelayan banyak & 0.10 & 3.40 & 0.335 \\
S5 & Adanya dukungan pemerintah & 0.09 & 3.20 & 0.297 \\
\hline Weaknesses (Kelemahan) & & & \\
\hline W1 & Armada tangkap tidak memadai & 0.06 & 2.20 & 0.140 \\
W2 & Ketersediaan Es tidak memadai & 0.05 & 1.70 & 0.084 \\
W3 & Tingginya harga BBM & 0.04 & 1.50 & 0.065 \\
& Pemahaman nelayan mengenai penanganan mutu ikan & & & \\
W4 & kurang & 0.08 & 2.60 & 0.196 \\
W5 & Jarak rumpon jauh & 0.07 & 2.30 & 0.153 \\
W6 & Armada pengawasan kurang & 0.07 & 2.40 & 0.167 \\
W7 & Infrastruktur belum lengkap & 0.06 & 2.10 & 0.128 \\
& Jumlah rumpon berbanding terbalik dengan jumlah & & & \\
W8 & armada & 0.07 & 2.50 & 0.181 \\
\hline & $\quad$ Total & $\mathbf{1 . 0 0}$ & & $\mathbf{2 . 8 3 4}$ \\
\hline
\end{tabular}

Table 4. Matriks faktor eksternal (IFAS) perikanan tuna di Kabupaten Pulau Morotai

\begin{tabular}{llccc}
\hline \multicolumn{5}{c}{ FAKTOR STRATEGI EKSTERNAL } \\
\hline Opportunities (Peluang) & Bobot & Peringkat & Skor \\
\hline O1 & Stok Ikan melimpah (pemanfaatan baru 5\%) & 0.14 & 4.00 & 0.576 \\
O2 & Prospek nelayan tuna cerah & 0.13 & 3.60 & 0.466 \\
O3 & Investor luar negeri & 0.10 & 2.90 & 0.303 \\
O4 & Permintaan pasar tinggi & 0.14 & 3.90 & 0.547 \\
O5 & Nilai jual tinggi & 0.14 & 4.00 & 0.576 \\
O6 & Terbentuknya lembaga/koperasi perikanan & 0.12 & 3.30 & 0.392 \\
\hline Threats (Ancaman) & & & \\
\hline T1 & Nelayan andon (neleyan luar) & 0.05 & 1.50 & 0.081 \\
T2 & Kapal kapasitas lebih besar & 0.07 & 2.00 & 0.144 \\
T3 & Lemahnya pengawasan & 0.09 & 2.60 & 0.243 \\
\hline \multicolumn{2}{c}{ Total } & $\mathbf{1 . 0 0}$ & $\mathbf{3 . 3 2 7}$ \\
\hline
\end{tabular}

\subsection{Analisis SWOT}

Alternatif strategi pengelolaan perikanan tuna diperoleh dengan menggunakan metode analisis SWOT. Ridarwati et al (2010) mengemukakan bahwa keberlanjutan penelolaan perikanan ke arah yang lebi baik dibutuhkan suatu alternative strategi pengelolaan.Matriks SWOT dari pengelolaan perikanan tuna dapat dilihat pada Table 5.

Tabel 5. Matriks SWOT

\begin{tabular}{|l|l|l|}
\hline & Strength (S) - Kekuatan & Weaknesses (W) - Kelemahan \\
& a. Potensi Sumberdaya Ikan Besar & a. Armada tangkap tidak memadai \\
& b. Nilai Jual Tinggi & b. Ketersediaan Es tidak memadai \\
& c. Potensi SDM Memadai & c. Tingginya harga BBM \\
& d. Jumlah nelayan banyak & demahaman nelayan mengenai \\
& e. Adanya dukungan pemerintah & e. Jarak rumpan mutu ikan kurang \\
\hline
\end{tabular}




\begin{tabular}{|c|c|c|}
\hline & & $\begin{array}{ll}\text { f. } & \text { Armada pengawasan kurang } \\
\text { g. Infrastruktur belum lengkap } \\
\text { h. Jumlah rumpon berbanding } \\
\text { terbalik dengan jumlah armada }\end{array}$ \\
\hline $\begin{array}{l}\text { Opportunities (O)- Peluang } \\
\text { a. Stok Ikan melimpah } \\
\text { b. Prospek nelayan tuna cerah } \\
\text { c. Investor luar negeri } \\
\text { d. Permintaan pasar tinggi } \\
\text { e. Nilai jual tinggi } \\
\text { f. Terbentuknya } \\
\text { lembaga/koperasi perikanan }\end{array}$ & $\begin{array}{l}\text { Strategi (SO) } \\
\text { 1. Menerapan model pengelolaan } \\
\text { perikanan tuna terpadu } \\
\text { 2. Membuka peluang pasar melalui } \\
\text { penetapan alur bisnis perikanan Tuna } \\
\text { dengan investor dari luar Kabupaten } \\
\text { Pulau Morotai (Dalam maupun Luar } \\
\text { Negeri) } \\
\text { Manajemen pengelolaan yang baik, } \\
\text { melalui program Koperasi nelayan }\end{array}$ & $\begin{array}{ll} & \text { Strategi (WO) } \\
\text { 1. } & \text { pembangunan SPBU nelayan } \\
\text { 2. } & \begin{array}{l}\text { Pembangunan infratruktur } \\
\text { (coolstorage) }\end{array} \\
\text { 3. } & \begin{array}{l}\text { memaksimalkan pendampingan } \\
\text { nelayan melalui program } \\
\text { penyuluh perikanan }\end{array}\end{array}$ \\
\hline $\begin{array}{l}\text { Threats (T) - Ancaman } \\
\text { a. Nelayan andon (neleyan } \\
\text { luar) } \\
\text { b. Kapal kapasitas lebih besar } \\
\text { c. Lemahnya pengawasan } \\
\end{array}$ & $\begin{array}{l}\text { Strategi (ST) } \\
\text { Meningkatkan skill nelayan melalui } \\
\text { pelatihan-pelatihan berbasis teknologi }\end{array}$ & $\begin{array}{l}\text { Strategi (WT) } \\
\text { 1. Revitalisasi armada tangkap dari } \\
\text { 3-5 GT menjadi } 15-30 \mathrm{GT} \\
\text { 2. Meningkatkan sistem } \\
\text { pengawasan di perairan } \\
\end{array}$ \\
\hline
\end{tabular}

\subsection{Strategi Pengelolaan}

Berdasarkan analisis SWOT diperoleh alternatif strategi pengelolaan perikanan tuna di Kabupaten Pulau Morotai.Terdapat empat alternatif strategi pengelolaan yaitu strategi SO (strength-opportunities), strategi ST (strength-threats), strategi WO (weaknesses-opportunities), dan strategi WT (weaknesses-threats).Pembobotan dan pemberian skor di setiap faktor dapat menentukan strategi prioritas bagi pengelolaan perikanan tuna.Penentuan strategi prioritas dilakukan dengan meletakan hasil skoring pada matriks grand strategy. Yahya et al (2013) menyebutkan bahwa penetapan matriks grand strategy dilakukan untuk memilih strategi prioritas dari keempat strategi hasil dari analisis SWOT. Matriks grand strategy pengelolaan perikanan tuna di Kab.Pulau Morotai dapat dilihat pada Gambar 2.

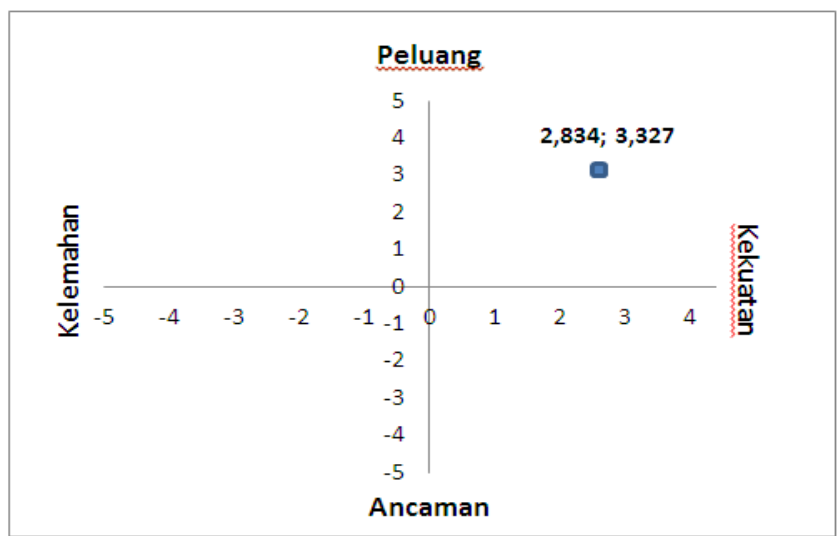

Gambar 2.Matriks grand strategy pengelolaan perikanan tuna di Kab. Pulau Morotai

Gambar 2.menunjukan bahwa posisi strategi berada di kuadran I. Hasil ini diperoleh berdasarkan analisis SWOT yang berlandaskan pada data yang diperoleh di lapangan bahwa strategi prioritas dalam pengelolaan tuna di Kab. Pulau Morotai adalah strategi SO. 
ISSN 2620-570X

JURNAL IlMu KelaUtAN KEPULAUAN, 1 (2) ;22-29, DeSEMBER 2018

Adapun strategi prioritas dalam upaya pengelolaan perikanan tuna di Kab. Pûau Morotai adalah sebagai berikut:

\section{Menerapan model pengelolaan perikanan tuna terpadu}

Menurut Nikijuluw (2002), sumberdaya perikanan sangat sensitif terhadap perbuatan manusia, oleh karena itu sumberdaya perikanan harus dikelola dengan baik. Dibutuhkan suatu pendekatan pengelolaan sehingga dalam pemanfaatan sumberdaya perikanan tidak dilakukan secara berlebihan dan menyebabkan terjadinya tekanan secara ekologi dan menurunkan kualitasnya.Pasal 2 UU Perikanan no 45 tahun 2009 menyebutkan bahwa pengelolaan perikanan dilakukan berdasarkan asas manfaat, keadilan, kemitraanm pemerataan, keterpaduan, keterbukaan, efisiensi, dan kelestarian yang berkelanjutan.

Tuna merupakan komoditi penting di Indonesia dengan target ekspor. Sehingga dalam pemanfaatan sumberdaya ikan ini dibutuhkan suatu model pengelolaan yang mencangkup semua faktor.Kabupaten Pulau Morotai secara keseluruhan belum mempunyai model pengelolaan perikanan tuna.Namun, Kementerian Kelautan Perikanan (KKP) melalui program Sentra Kelautan dan Perikanan Terpadu (SKPT) menjadikan tuna sebagai fokus pengelolaan. Dengan demikian meskipun belum mempunyai model pengelolaan tuna yang paten, namun sumberdaya tuna di Kab.Pulau Morotai dapat dikelola dengan baik.Diharapkan kedepan Kabupaten Pulau Morotai dapat memiliki satu model pengelolaan khusus untuk sumberdaya ikan tuna.

\section{Membuka peluang pasar melalui penetapan alur bisnis perikanan tuna dengan investor dari luar Kabupaten Pulau Morotai (dalam maupun luar negeri)}

Umar (2012) mengemukakan bahwa terdapat dua faktor yang mempengaruhi peluang bisnis kelautan perikanan, terdiri dari: (1) faktor internal berupa potensi sumberdaya alam, potensi sumberdaya manusia, teknologi, sarana dan prasarana, serta pemasaran; (2) faktor eksternal yang berkaitan dengan aspek permintaan serta syarat-syarat yang menyertai permintaan produk kelautan perikanan. Memiliki salah satu sumberdaya ikan ekonomis penting, mengharuskan Kabupaten Pulau Morotai mampu mengelola bisnis perikanan tuna.Hasil tangkapan tuna di perairan morotai dijual di pasar lokal dan pasar luar melalui kerjasama dengan investor.PT Harta Samudra merupakan salah satu perusahaan yang memiliki kerjasama dengan Pemerintah Daerah Kabupaten Pulau Morotai untuk menyalurkan hasil produksi tuna ke pasar di luar morotai (dalam maupun luar negeri).

Lestari et al (2013) mengemukakan bahwa Jemang, Uni Eropa, dan Amerika merupakan beberapa negara tujuan ekspor sebagian besar produksi tuna di Indonesia.Melalui SKPT KKP dan kerjasama dengan PT Harta samudra, hasil produksi tuna yang diolah menjadi loin telah diekpor ke negara Vietnam.Dengan demikian peluang pasar bagi nelayan tuna sudah sangat menjanjikan.Melalui pengelolaan bisnis yang baik, segala unsur usaha perikanan tuna mulai dari nelayan, pengempul, maupun distributor dapat memperoleh kesejahteraan.

\section{Manajemen pengelolaan yang baik, melalui program Koperasi nelayan}


ISSN 2620-570X

JURNAL IlMu KelaUtAN KEPULAUAN, 1 (2) ;22-29, DeSEMBER 2018

Program koperasi nelayan merupakan salah satu program yang dicanangkan ôeh Bupati Kab.Pulau Morotai yang telah dilaksanakan.Saat ini dari 88 desa sudah ada 36 desa yang telah memiliki koperasi nelayan.Adanya koperasi nelayan dapat membantu nelayan dalam memanajemen usaha penangkapan yang mereka geluti.

\section{Kesimpulan}

Kesimpulan yang didapat dari penelitian ini adalah strategi prioritas pengelolaan perikanan tuna di Kabupaten Pulau Morotai terdiri dari:

1. Menerapan model pengelolaan perikanan tuna terpadu

2. Membuka peluang pasar melalui penetapan alur bisnis perikanan Tuna dengan investor dari luar Kabupaten Pulau Morotai (Dalam maupun Luar Negeri)

3. Manajemen pengelolaan yang baik, melalui program Koperasi nelayan

\section{Ucapan terima kasih}

Ucapan terima kasih penulis sampaikan pada pihak-pihak yang berperan dalam pelaksanaan penelitian ini antara lain:

1. KEMENRISTEK DIKTI sebagai pemberi dana penelitian.

2. Pimpinan Universitas Pasifik Morotai dan jajarannya atas dukungan moril yang diberikan kepada penulis selama penelitian berlangsung.

3. Dinas Kelautan dan Perikanan Kab. Pulau Morotai, Koperasi Tuna Pasifik, Koperasi Taruna Selatan, dan seluruh nelayan tuna yang menjadi narasumber selama penelitian berlangsung.

4. Pihak-pihak yang terlibat langsung maupun tidak langsung membatu penulis selama penelitian.

\section{Daftar pustaka}

[BPS] Badan Pusat Statistik Kabupaten Pulau Morotai. 2015. Morotai Dalam Angka

Nurani T.W. 2010. Model Pengelolaan Perikanan Suatu Kajian Pendekatan Sistem. Bogor (ID). Intermedia-Bogor

Lestari W, Syarief R, dan Sumantadinata K. 2013. Strategi Peningkatan Daya Saing Tuna Olahan Indonesia di Pasar Internasional. Manajemen IKM. 8(1): 36-44

Ridarwati S, Baskoro M.S, Monintja D. R, dan Purbayanto A. 2010.Analisis Faktor InternalEksternal dan Status Keberlanjutan Pengelolaan Perikanan Tangkap di teluk Jakarta.Jurnal Teknologi Perikanan dan Kelautan. 1(1):1-13

Sofiati T.2016. Analisis Komoditas Unggulan Perikanan tangkap di Kabupaten Pulau Morotai. Unipas Press. 1(1): 1-9

Umar Zainal A. 2012. Strategi Bauran Pemasaran Dalam Meningkatkan Volume Penjuakan Ikan Tuna Olahan Pada PT. Betel Citra Seyan Gorontalo. Jurnal Inovasi. 9(1): 1-26

Yahya E, Rosyid A, dan Suherman A. 2013. Tingkat pemanfaatan fasilitas Dasar dan Fungsional Dalam Strategi Peningkatan Produksi di Pelabuhan Perikanan Pantai Tegalsari Kota Tegal Jawa Tengah.Journal of Fisheries Resources Utilization Management and Technology. 2(1):56-65 